\title{
The Values of Political Reconciliation
}

\author{
Alice MacLachlan
}

\begin{abstract}
A review of A Moral Theory of Political Reconciliation by Colleen Murphy (Cambridge University Press, 2010), 220 pp, ISBN 978-0521 193924.
\end{abstract}

Political communities in transition face a number of political, social and legal challenges, ranging from democratisation and disarmament to the rebuilding of basic infrastructure and civil society. In recent years, activists, experts and politicians have come to focus on the significant value of political reconciliation for those faced with these challengesboth instrumentally, as a condition of further peacemaking and democratisation, and for its own sake. Just what we mean — or what we ought to mean-by'political reconciliation' is not only a matter of theoretical speculation, therefore; clarifying this concept helps to establish appropriate frameworks and goalposts for the very practical work of post-conflict social repair. Colleen Murphy's clear and compelling account thus makes a much-needed contribution to philosophical discussions of reconciliation and, potentially, to future policy-making.

The body of A Moral Theory of Political Reconciliation is divided into two parts, each consisting of three chapters; these are preceded by an extended, philosophically rich introduction. In the first part ('Conceptual Frameworks'), Murphy presents her theory of political reconciliation. The theory itself is divided into three distinct normative frameworks, each of which corresponds to particular relational damages that processes of political reconciliation must repair. In the second part ('Promoting Political Reconciliation'), she considers the application of these frameworks to actual processes of reconciliation, focusing on two recognisable vehicles of transitional justice: truth commission and international criminal trials.

In the opening pages of her introduction, Murphy dives directly into a conceptual problem plaguing philosophical discussions of reconciliation: while there are a growing number of theories of reconciliation available, it is often unclear how these diverge from one another - that is, whether proponents disagree over basic values and principles, and the application of these values, or whether they are simply choosing to focus on one aspect of a broader problem, to the exclusion of others. Thus, Murphy should be credited

York University, Toronto, Canada. Email: amacla@yorku.ca. 
for beginning with desiderata for an appropriate theory of political reconciliation. Such a theory should be normative (8), she argues, capable of guiding actions and policies and also of clarifying what is morally at stake. Second, it should be political and not derived from more general theories of moral reconciliation, since reconciliation concerns rebuilt relationships, and political relationships differ significantly from non-political ones (9). Finally, such a theory should be particularistic and responsive to the complex, diverse phenomena at hand. To understand the ideal of relational repair, we must start from the reality of relational rupture-philosophical theories of reconciliation must thus be not only capable of guiding practice, but also of responding to it.

At the heart of Murphy's theory is the claim that good political relationships express both reciprocity and respect for moral agency: 'reciprocal agency' (27). If, by political reconciliation, we mean those processes that rebuild damaged political relationships, then the goal of reconciliation (and-indeed-perhaps of normative politics more generally) is to create and maintain conditions under which political relationships can possess and express these values. A just and flourishing political community is one constituted and characterised by such relationships. Since political relationships have both institutional and attitudinal dimensions, Murphy offers us three different normative frameworks, which 'represent distinct ways in which political relationships can respect moral agency and reciprocity' (29) and the absence of which correspond to a 'specific dimension of the damage ... that stems from civil conflict and repressive rule' (188). These are:

1. The rule of law, interpreted via Lon Fuller's eight principles of legality: generality, publicity, non-retroactivity, clarity, non-contradiction, non-impossibility, constancy, and congruity (42-43).

2. Default attitudes of political trust and trust responsiveness: that is, 'an attitude of optimism with respect to the competence and will of other citizens and officials' (77), alongside the expectation that being trusted will 'provide a reason for proving reliable in the domain over which our trust extends' (74).

3. Support for individual political capabilities (drawing on Martha Nussbaum and Amartya Sen's capabilities theory); specifically: 'the capabilities of being respected; being recognized as a member of a political community; being an effective participant in the economic, social, and political life of the community; and fulfilling basic functionings that are necessary in order to survive and to escape poverty' (95).

Taken together, Murphy argues, these three frameworks provide appropriate theoretical resources for understanding both how political relationships go wrong and how they should be rebuilt in order to express reciprocal agency.

The first framework, the rule of law, focuses on the institutional dimensions of political damage. Murphy's discussion in Chapter One is largely an application and defence of Fuller's theory. She outlines Fuller's criteria, and-nicely employing the example of 
Argentina under military rule (1976-83) — she shows how Fuller's formal account draws our attention to the importance of law for political relationships. Argentinian policies ranging from massive state abductions to torture and detention were deeply harmful not only to the individuals directly affected, but also to 'the fabric of trust and reciprocity that underlies political relationships structured by law' (48). The chapter goes on to defend the non-instrumental value of the rule of law, conceived formally, answering objections that (i) law meeting Fuller's criteria can nonetheless be employed to pursue systematically unjust ends and (ii) that, when conceived formally and not substantively, the virtues of legality are negative. Fuller's eight principles sit in deep tension with the pursuit of injustice, and assist us in distinguishing between genuine legality and mere façade - only the latter is possible under conditions of conflict and repression. Ultimately, Murphy concludes, a formal account like Fuller's is most advantageous to theories of reconciliation, since it both 'captures the distinctive kind of social order law represents and, at the same time, prevents us from equating all the demands of political reconciliation with the demands of the rule of law' (69) - that the two are not equivalent is precisely why the second two normative frameworks are required.

In Chapter Two, Murphy turns from the institutional to the affective, interpersonal dimensions of political relationships, since-according to her own argument-attention to legality alone produces a minimalist account of reconciliation. To reconcile, we must do more than respect principles of legality; our political relationships must express trust. For Murphy, trust is 'an attitude of optimism with response to the competence and will of other citizens and officials', a 'hopeful anticipation' (77) that includes an expectation that the trusted party be 'trust-responsive', ie that she will be "'directly and favorably moved by the thought" that she is being counted on by the truster' (74). Political trust is grounded in the sense that others show 'a willingness to play fairly ... the absence of a desire to exploit the cooperation by others', as well as 'absence of a desire to harm or ... eradicate certain social, political, or ethnic groups' (78) — not to mention broad political competences: ie knowing what one's role entails, the knowledge required to fulfil it, and a real capacity to act on that knowledge. While others have written about the importance of trust for political reconciliation, Murphy's analysis explores the conditions under which attitudes of default political trust and trust-responsiveness are not only beneficial but warranted; relationships where trust is present but unreasonable are potentially as damaging as those characterised by distrust and suspicion. When trust is reasonable, it has both instrumental and non-instrumental value: facilitating efforts to rebuild and expressing respect for the agency of the trusted, as well as realising the value of reciprocity. Surprisingly, this chapter lacks the rich survey of global illustrations that can be found on almost every other page of the book-apart from a brief reference to a Sunni human rights worker (86), the reader is given little evidence of what failures of reasonable default trust look like on the ground.

Societies in transition do not only face corrupt laws and distrust; they are also rife with brutal and systematic violence, as well as deprivation and exclusion for the most 
powerless and marginalised. Murphy's third framework, political capabilities, is aimed at these relational harms. In Chapter Three, she first provides an overview of the capabilities theory established by philosophers Amartya Sen and Martha Nussbaum and draws out her own iteration (developed in previous work with Paolo Gardoni), which compares individual choices to the choices of others in similar circumstances. Murphy then focuses on four political capabilities which she takes to be constitutive of equals in a political community: being respected by others; participating in the social, economic and political life of a community; being recognised as a member of a political community; and surviving and escaping poverty. She goes on to show the myriad and overlapping ways in which these capabilities are diminished, distorted, and erased by systemic political violence, economic oppression, and unequal construction of group identity. Since damaged political relationships undermine these capabilities, the work of reconciliation rightly focuses on their repair.

For some, this third chapter may sit uneasily with Murphy's rejection of recognition and social justice as potentially useful normative frameworks in her introduction (35-36). There, she rejects the former because it assumes that understanding conflict and repression necessarily involves some appeal to social groups and identity, and the latter because she equates it with concern over the distribution of material and social goods. ${ }^{1}$ Murphy argues that neither condition - that is, neither social identities nor the distribution of goods-is necessarily a feature of political relational damage. Yet the claim that political strife does not involve social identities is only plausible if we restrict our understanding to ethnic or religious identities; once we acknowledge class, gender, and other social group identities that function as sources of oppression, that plausibility wavers. Indeed, Murphy herself references groups and sub-groups numerous times in her discussion of capabilities, and explicitly lists 'the inequitable construction of group identity' as one of three sources of damage (114). Similarly, her discussion of poverty classifies questions of justice in distribution as partly constitutive of what it means to be an equal, respected member of a political community. A better move would be to acknowledge the importance of both social identity and material goods to political relationships, but to argue that the capabilities framework is sufficient for addressing both, rendering recognition and social justice irrelevant. In choosing to express these concerns purely through the capabilities framework, however, Murphy makes herself vulnerable to familiar criticisms of it: namely, that it addresses questions of identity and distribution in a problematically individualist manner.

The second half of the book ('Promoting Political Reconciliation') shifts from the need for reconciliation to its process and application. In Chapter Four, Murphy presents a general framework for assessing how particular processes contribute to reconcilia-

1 Indeed, it is worth noting that this is a startlingly modest conception of social justice, which does not take account of the work done by figures like Nancy Fraser, Iris Marion Young and others, who argue that the distributive model is a profoundly inadequate picture of social justice. 
tion: considering both the identification of relevant contributions and the appropriate normative constraints governing them. A specific process-for example, a truth commission-may contribute directly to reconciliation, by cultivating respect for rule of law, increased (warranted) trust, or increased political capabilities, or it can make an indirect contribution. A process that creates hope or acknowledges the need for reconciliation may thereby assist in making that reconciliation possible-for instance, as does one that assists in developing the social and moral context to support rebuilt relationships.

At this point, the various strands of Murphy's overall normative picture come together: because the rule of law, warranted political trust and political capabilities each describe various ways in which political relationships express respect for agency and reciprocity, the general cultivation of respect for agency and reciprocity becomes part of the social and moral context in which each framework operates. Additionally, each framework has more specific conditions, ranging from ongoing cooperative activity to attitudes of openness to change and institutional reform. Finally, she concludes, in making decisions about which processes to implement, we must attend to the particular character of conflict and repression in each specific case, as well as the kinds of transformation a given process is likely to produce-here, social scientific research may be of use to philosophers and policy-makers. Furthermore, policies of reconciliation must make ongoing decisions of prioritisation and must not overlook the individuals who participate in them (in the case of truth commissions and trials, for example, those who testify). Murphy is explicit that her general framework is just that — general—and is not intended to be public policy analysis. Nevertheless, her insistence on an ongoing focus on the particular (particular processes, contexts and individuals) is a refreshing change from a tendency towards unhelpful generality in the philosophical literature on reconciliation.

The final two chapters round out Murphy's analysis by applying her framework to two familiar mechanisms in order to demonstrate their potential contribution to political reconciliation: truth commissions (Chapter Five) and international criminal trials (Chapter Six). The strengths and weaknesses she attributes to each mechanism will be familiar to those versed in the relevant literatures. Her discussion of narrative and group identity in Chapter Five is particularly insightful, drawing on illustrations from ongoing conflicts between Catholics and Protestants in Northern Ireland as these are expressed in parade, song, and story. She also highlights the importance of remembrance for reconciliation, and identifies the difficulties associated with telling appropriately complex and diverse truths through multiple testimonies. In Chapter Six, she turns from local political communities to the role of global political communities, describing a role for international players in establishing the social conditions of law. While criminal trials may not appear especially reconciliatory at first glance, Murphy emphasises their potential educative, expressive, and communicative roles, and addresses objections regarding the practice of such trials (ranging from issues of due process and the treatment of perpetrators to conflicts between local and international personnel). Though these two chapters 
lack the strong originality of the rest of the book, they nevertheless function as clear, concrete applications of her deeply appealing normative framework to well-established transitional mechanisms. My only real disappointment lies with her choice of applications. One of the most novel and compelling aspects of Murphy's overall analysis is her insistence on the interpersonal and attitudinal dimensions of political relationships; for her, such relationships cannot be understood only in terms of institutions and formal roles. It is perhaps regrettable, therefore, that when implementing her normative framework she focuses only on two highly institutional mechanisms; I was especially curious to see how her emphasis on trust and on individual beings and doings might redirect our attention away from larger institutions of reconciliation to practices of reconciliation as these occur in smaller, local contexts.

A Moral Theory of Political Reconciliation offers theorists and practitioners of reconciliation a wealth of thoughtful insights and useful theoretical tools for navigating the murky waters of post-conflict repair. It also invites us to rethink the nature of political relationships more generally, both as they ought to be and as they fall away from this ideal. Finally, Murphy's desiderata for a theory of political reconciliation and her own answers to those desiderata raise the bar for future philosophical interventions. For all these reasons, her book is a welcome addition to ongoing discussions of political transitions. 